\title{
Comparative study of low dose magnesium sulphate regime with Pritchard regime in eclampsia
}

\author{
Patil $\mathbf{M}^{1}$, Dube A. $\mathbf{H}^{2}$, Purwar $\mathbf{M}^{3}$ \\ ${ }^{1}$ Dr. Madhuri Patil, Assistant Professor, Department of Obstetrics \& Gynecology, IGGMC, Nagpur, ${ }^{2}$ Dr. A H Dube, \\ Associate Professor, Medicine, GMC, Chandrapur, ${ }^{3}$ Dr. M Purwar, Ex. Professor, Department of Obstetrics \& \\ Gynecology, IGGMC, Nagpur, Maharashtra, India.
}

Address for Correspondence: Dr. Madhuri Patil, Email: patilmadhuri303@gmail.com

\begin{abstract}
Introduction: Eclampsia is still a leading cause of maternal mortality and morbidity. Magnesium sulphate despite being an anticonvulsant of choice remains underutilized due to fear of toxicity. Average weight of Indian women is less than the western women due to which lower dose of magnesium sulphate can be used in treatment of eclampsia. The aim of the study was to compare the efficacy of low dose magnesium sulphate regimen with Pritchard regimen, in the control of convulsion in eclampsia. We also compared neonatal and maternal outcome in these two group. Methodology: This randomized control study was carried out at Emergency Labour room, Government Medical College, Nagpur. 160 patients of eclampsia were divided randomly into study group $(\mathrm{n}=80)$ receiving low dose $\mathrm{MgSO} 4$ and control group $(n=80)$ receiving Pritchard regimen. The recurrence of convulsion, toxicity profile and maternal and fetal outcome was studied. Results: Majority of patients $73.75 \%$ were primigravida and $77.5 \%$ unbooked cases. $91.5 \%$ had antepartum/intrapartum eclampsia. $6(7.5 \%)$ patients in study group had recurrence of convulsion as compared to 11 $(13.75 \%)$ in Pritchard regimen group $(\mathrm{p}=0.31)$. Toxicity of MgSO4 in the form of lost tendon reflexes and respiratory depression was significantly less in those receiving Low dose of MgSO4 $(\mathrm{p}<0.001)$. Respiratory depression developed in one patient in control group and none in study group. Maternal mortality was $2.5 \%$ in both the groups. Perinatal mortality was $28.75 \%$ in the study group and $33.73 \%$ in control group. Conclusions: Low dose Magnesium sulphate regimen was equally effective in the control of convulsions in eclampsia and can be safely used in Indian women.
\end{abstract}

Key words: Eclampsia, Low dose, Magnesium sulphate

\section{Introduction}

Eclampsia is an obstetric enigma. It is one of the important causes of maternal and neonatal mortality and morbidity. Worldwide 50,000 deaths occurred due to eclampsia [1]. In developed country incidence had fallen considerably due to improved prenatal care. But in developing countries eclampsia incidence is still high. Reports published from 1976 to 2015 reveal that incidence of eclampsia in India ranges from 0.179 to $5 \%$, the average being $1.5 \%$ [2]. Magnesium Sulphate is drug of choice and most preferred regimen is Pritchard regimen [3]. Jack A. Pritchard popularized magnesium sulfate therapy in eclampsia in modern obstetrics since 1975. But doubt still persists regarding suitable dose of

Manuscript received: $10^{\text {th }}$ April 2017

Reviewed: $19^{\text {th }}$ April 2017

Author Corrected: $27^{\text {th }}$ April 2017

Accepted for Publication: $4^{\text {th }}$ May 2017
$\mathrm{MgSO}_{4}$ because serum magnesium level varies according to (maternal) weight [4]. Pritchard regime was formulated for woman weighing average $70 \mathrm{~kg}$. But an Indian woman has an average weight of $49.4 \pm 7.18$ $\mathrm{kg}$ [5]. Witling also recommended an adjustment of dose according to patient's body mass index [6].

This initiated a research to modify the dose of magnesium sulphate in eclampsia.

\section{Materials and Methods}

Study Design:-This randomized case-control study was carried out in the department of Obstetrics and Gynecology, Government Medical College \& Hospital, Nagpur. 
Study Setting:- Emergency Labor room/eclampsia room.

Study period:- June 2005 to November 2006

Approval was taken from Institutional Ethics committee of Government medical college Nagpur.

Study population/participants: All eclampsia patients, antepartum, intrapartum and postpartum, admitted in Emergency labor room.

Inclusion criteria: Diagnosed case of Eclampsia: Diagnosis of eclampsia has been established in accordance with National High Blood Pressure Working Group Report on High blood pressure in Pregnancy.

Exclusion Criteria: 1) Known case of epilepsy, 2) Meningitis and encephalitis, 3) Intracranial tumor or SOL.

Informed consent was obtained from the spouse or patient's nearest relative.

Detailed clinical examination was carried out in all the patient along with relevant investigation which include complete haemogram, KFT, LFT, Coagulation profile, fundus examination y \& urine analysis.

Sample size- Sample size was calculated by assuming the power $80 \%$. While considering the recurrence rate with Pritchard regime 10-20\% and recurrence rate with low dose regime $7.89 \%$, sample size was calculated as 160. According to randomization, they were allocated into 80 each in study and control group.

Randomization- At the time of admission the eclampsia patients were allocated to either study group or control group by tossing method.

Study group: Eclampsia patient received low dosage magnesium sulfate regime

Control group: received Pritchard regime.

*Protocol for low dose $\mathrm{MgSO}_{4}[5]$

\section{Results}

There were 180 cases of eclampsia among 24,680 deliveries at our institute which gave an incidence of $0.72 \%$.
Loading dose: 4 gram (20\%) of $\mathrm{MgSO}_{4}$ (7.H2O) diluted in $12 \mathrm{cc}$ of distilled water slowly intravenously over 15-20 minutes.

Maintenance dose: 2 gram (50\%) of $\mathrm{MgSO}_{4}$ given intramuscularly every 3 hourly was continued for $24 \mathrm{hr}$ after delivery or after last convulsion which ever occur later.

For Recurrence of convulsion: If the convulsion occurred half an hour after receiving loading dose called recurrence of convulsion, additional dose of $2 \mathrm{gm}$ $(20 \%)$ of $\mathrm{MgSO}_{4}$ given I.V. diluted in $6 \mathrm{cc}$ of distilled water. If again the recurrence of convulsion occurs, another anticonvulsant drug, Inj. Phenytoin Sodium $100 \mathrm{mg}$ was added intravenously.

Before giving each dose of $\mathrm{MgSO}_{4}$ following parameter were checked

1. Knee Jerk (patellar reflex)

2. Urine output - It should be more than $100 \mathrm{ml}$ in $4 \mathrm{hr}$ or more than $30 \mathrm{ml} / \mathrm{hr}$

3. Respiratory rate- more than 16

Anti hypertensive therapy: Nifedipine $10 \mathrm{mg}$ was given either sublingually or orally as an adjuvant for control for hypertension. Hydration was maintained by Ringer lactate solution $1000 \mathrm{cc}$ over $24 \mathrm{hr}$.

When the patient was stabilized obstetric management was carried out according to bishop score, gestation age $\&$ viability of fetus.

Outcome measures: (1) Recurrence of convulsion, (2) Toxicity profile, (3) Maternal mortality and morbidity, (4) HELLP, (5) DIC(Disseminated Intravascular coagulation), (6) Pulmonary edema, (7) Intra cranial hemorrhage, (8) Post partum hemorrhage.

Perinatal Outcome was measured as (1) Still birth, (2) Low birth weight and (3) Neonatal death.

Statistical Analysis: Mean, Standard deviation and P value was calculated using statistical formulas (epi-info software). T-test, z-test and Chi-square test was used. $\mathrm{P}$ value $<0.05$ was called as statistically significant. 
Table-1: Demographic profile of cases \& controls.

\begin{tabular}{|c|c|c|}
\hline Variables & Study group Cases $(\mathbf{n}=\mathbf{8 0})$ & Control group $(\mathbf{n}=\mathbf{8 0})$ \\
\hline Age(years) $\pm \mathrm{SD}$ & $23.5 \pm 2.7$ & $23.4 \pm 3.04$ \\
\hline Weight(Kg) $\pm \mathrm{SD}$ & $47.4 \pm 4.35$ & $48.37 \pm 5.8$ \\
\hline Gestational age(wks) & 36.9 & 37 \\
\hline Unbooked patients (unsupervised) $(\%)$ & $61(76.25 \%)$ & $63(78.75 \%)$ \\
\hline Primigravida (Parity)(\%) & $59(73.75 \%)$ & $58(72.5 \%)$ \\
\hline
\end{tabular}

Patients were weighted on $3^{\text {rd }}$ and $4^{\text {th }}$ day of delivery when ambulatory. Average weight in study and control group was $47.4 \pm 4.35 \mathrm{~kg}$ and $48.37 \pm 5.84 \mathrm{~kg}$ respectively. Weight distribution in study and control group was similar. Mean gestational age in the study and control group was 36.9 weeks and 37 weeks respectively. Most of eclapmsia patients were primigravida $73.75 \%$ and $72.5 \%$ in study and control group respectively. Most of the eclampsia patients, total 124 $(77.5 \%)$ out of 160 had unsupervised pregnancy.

Table-2: Types of Eclampsia in Study and Control group.

\begin{tabular}{|c|c|c|c|}
\hline Type of Eclampsia & $\begin{array}{c}\text { Study group } \\
(\mathbf{n = 8 0})\end{array}$ & $\begin{array}{c}\text { Control group } \\
(\mathbf{n = 8 0})\end{array}$ & $\begin{array}{c}\text { TOTAL } \\
\mathbf{1 6 0}\end{array}$ \\
\hline Antepartum /Intrapartum & $74(92.5 \%)$ & $72(90 \%)$ & $146(91 \%)$ \\
\hline Postpartum & $6(7.5 \%)$ & $8(10 \%)$ & $14(9 \%)$ \\
\hline
\end{tabular}

$74(92.5 \%)$ patients of study group and 72 of control were having antepartum/ intrapartum eclampsia. Only 6 among the study group and 8 among control developed total $9 \%$ developed convulsions after delivery.

Table-3: Recurrence of convulsions in Study \& Control group.

\begin{tabular}{|c|c|c|c|}
\hline Convulsions & Study group $(\mathbf{n}=\mathbf{8 0})$ & Control group $(\mathbf{n}=\mathbf{8 0})$ & P val \\
\hline None & $74(92.50 \%)$ & $69(86.25 \%)$ & \\
\hline One & $4(5 \%)$ & $11(13.75 \%)$ & $\mathrm{p}=0.31$ \\
\hline Two & $2(2.50 \%)$ & 0 & \\
\hline
\end{tabular}

Control of convulsions after receiving loading dose was $92.5 \%$ in study group and $86.25 \%$ in control group. 6 cases in study group and 11 in control group had recurrence of convulsions which was controlled with one or two additional doses of MgSO4 doses and the difference was statistically not significant.

Table-4: Toxicity profile in Study and Control group.

\begin{tabular}{|c|c|c|c|}
\hline Toxicity profile & Study group $(\mathbf{n = 8 0})$ & $\begin{array}{c}\text { Control group } \\
(\mathbf{n = 8 0})\end{array}$ & \multirow{2}{*}{ P value $<\mathbf{0 . 0 0 1}$} \\
\hline DTR absent & $6(7.5 \%)$ & $28(35 \%)$ & \\
\hline Respiratory depression & 0 & 0 & \\
\hline Coma & 0 & $\mathbf{2 9}$ & \\
\hline Total & $\mathbf{6}$ & $(1.25 \%)$ & \\
\hline
\end{tabular}

(DTR-Deep tendon reflexes)

Difference in toxicity was statistically highly significant (p < 0.001) Absent DTR was in seen in $7.5 \%$ and $35 \%$ in study and control group respectively. One patient in control group developed respiratory depression needing assisted ventilation and calcium gluconate supplement. Thus the difference in toxicity was statistically highly significant. 
Table-5: Maternal Complications.

\begin{tabular}{|l|c|c|}
\hline Causes & Study group $(\mathbf{n = 8 0})$ & Controls $(\mathbf{n = 8 0})$ \\
\hline 1. Mortality & $2(2.5 \%)$ & $2(2.5 \%)$ \\
\hline 2. DIC & $5(6.25 \%)$ & $2(2.5 \%)$ \\
\hline 3. Pulmonary odema & $1(1.25 \%)$ & $2(2.5 \%)$ \\
\hline 4. APH & 0 & $2(2.5 \%)$ \\
\hline 5. HELLP & $1(1.25 \%)$ & $3(3.75 \%)$ \\
\hline 6. Intracranial Hemorrhage & $1(1.25 \%)$ & 0 \\
\hline 7. LVF & 0 & $1(1.25 \%)$ \\
\hline
\end{tabular}

(APH-Antepartum Hemorrhage, LVF-Left ventricular failure, DIC-Disseminated Intravascular coagulation)

Maternal mortality was equal in both group $2.5 \%$. It was due to complication of eclampsia .In study group 8 patient $\& 10$ patient in control group developed complication. The study group cause of death in first patient was HEELP with DIC with PCF (peripheral circulatory failure) and other had intracranial hemorrhage. Maternal mortality in the control group was 2 (2.5\%). Cause of death was LVF with pulmonary edema and other patient DIC (Disseminated Intravascular coagulation) with hypoxic brain injury. 5 cases in study group and 2 in control developed DIC.

\section{Table-6: Perinatal Outcome.}

\begin{tabular}{|c|c|c|c|}
\hline & Preterm/Term & Study group $(n=80)$ & Control $(n=80)$ \\
\hline \multirow{3}{*}{ 1.Livebirth } & & $64(80 \%)$ & $61(73.50 \%)$ \\
\hline & Preterm & 10 & 7 \\
\hline & Term & 47 & 48 \\
\hline \multirow[t]{3}{*}{ 2.Stilbirth } & & $16(20 \%)$ & $22(26.50 \%)$ \\
\hline & Preterm & 12 & 13 \\
\hline & Term & 4 & 9 \\
\hline \multirow[t]{3}{*}{ 3.Neonatal Death } & & $7(11.25)$ & $6(7.22 \%)$ \\
\hline & Preterm & 5 & 5 \\
\hline & Term & 2 & 1 \\
\hline 4.Perinatal Mortality & & $23(28.75 \%)$ & $28(33.73 \%)$ \\
\hline
\end{tabular}

$(P$ value $=\mathbf{0 . 8 6})$

$64(80 \%)$ out of 80 in study group and 61(73.5\%) out of 83 in control group had Live birth. Perinatal mortality in study group was $23(\mathbf{2 8 . 7 5 \%})$. There were 16 Stillbirths, out of these 12 were preterm and 4 were IUD. 2 Intrapartum deaths, one due to complication of forceps and other due to birth asphyxia. Perinatal outcome in the form of live births was $80 \%$ and $76 \%$ respectively in study and control groups. In the control group perinatal mortality was $\mathbf{2 8}(\mathbf{3 3 . 7 3 \% )} .22$ were stillbirths out of them 13 were preterm and 9 were term. 10 were IUD. Maximum fetus weighted $<1.5 \mathrm{~kg}$. 4 were intrapartum death. Neonatal deaths were 6; 5 were preterm and 1 was term. Cause of death in most of the neonates was prematurity.

\section{Discussion}

Magnesium sulphate has been recommended by WHO as the effective and safe drug for prevention and control of convulsions in eclampsia [7]. Suman Sardesai et al proved low dose Magnesium sulphate regimen was as effective as Pritchard regimen in control of convulsions in Indian women weighing average $48.4 \pm 6.7 \mathrm{~kg}$. Considering the effectiveness of this regimen the present study was undertaken [5]. Average maternal weight in the study and control group was $47.4 \pm 4.35$ $\mathrm{kg}$ and $48.37 \pm 5.8 \mathrm{~kg}$ respectively. There was no statistically significant $(p=0.23)$ difference. This was similar to mean weight reported in other Indian studies. Whereas due to good antenatal care in developed country like UK its $0.05 \%$. Majority of cases in study 
group were antepartum and intrapartum eclamsia. Similar observations were found in other Indian studies [8,9,10,11]. Eclampsia a disease of primigravida, incidence was $73.75 \%$ in our study, $89.7 \%$ in Jana et al, $75 \%$ in Pritchard. Similar observations were made by other authors [12,13,14,15].

Most of our patients of eclampsia were unbooked (unregistered with health system) and never received any antenatal checkup which remains the cornerstone in prevention of eclampsia. Similar observation were found in Ekelea et al and other studies [16,11,9].

Eclamsia is a sequel to uncontrolled and elevated blood pressure therefore regular ANC screening and treatment of pre-eclampsia remains the key factors in treatment of Eclampsia. The Collaborative group had concluded that there was compelling evidence in favor of magnesium sulphate for treatment of eclampsia but it was seen that healthcare personal are reluctant to administer it, prefer Diazepam or phenytoin sodium due to fear of potential toxicity of MgSO4. Timely managed (by giving loading dose) and early referral/ transportation of these patients to hospital could prevent maternal and foetal catastrophe, if $\mathrm{MgSO} 4$ given at primary health care in low dose without fear. Magnesium has narrow therapeutic index (4-7 meq/L). A higher number of patients lost DTR with Pritchard regimen than low dose regimen with Begum et al \& Shilva et al [17].

Respiratory depression is a major threat while using $\mathrm{MgSO} 4$. One patient of control group developed respiratory depression while 3 cases developed respiratory depression with Pritchard regimen. None developed respiratory depression with low dose regimen in present study $[4,8,9,18]$.

Seizures were well controlled in study group except in $7.5 \%$ who developed recurrence of convulsion. Similar observations seen in Suman Sardesai, Ruchira Nautiya while Begum et al reported only one case of recurrence. Recurrence rate with Pritchard regimen was 10 to $20 \%$ quoted by Pritchard et al and Sibai et al. It therefore seems that a lower dose of $\mathrm{MgSO} 4$ was equally effective in managing eclamptic convulsions [19].

Maternal mortality due to eclampsia ranges from 0.4$1.4 \%$ depending on severity of organ damage and delay in treatment. In present study maternal mortality was similar in study and control group. No maternal mortality was observed with Rashida et al and Ruchira et al. Jana et al observed low maternal mortality $[8,9,12]$. In present study perinatal mortality in study and control group was $28.75 \%$ \& $33.73 \%$ respectively. Perinatal mortality was $16 \%$ with Rehan Ahmad, $33.78 \%$ Suman Sardesai and 32\% Shiva [5,13,17].

\section{Conclusions}

1) Low dose regimen is a viable alternative to standard dose of Pritchard regimen in cases of eclamptic women in developing countries. It should be used in all general hospitals and tertiary care centers.

2) Due to low toxicity profile and equally effective compared to Pritchard regimen low dose $\mathrm{MgSO} 4$ should be used at primary health centre and rural hospitals before referrals.

3) Being a comparative study between two widely popular regimens with small sample the findings need to be confirmed in large multicentre trial.

\section{Funding: Nil, Conflict of interest: None Permission of IRB: Yes}

\section{References}

1. Maternal mortality- revised WHO estimates alarming. Indian Med Trib. 1996 Jun 15;4(11):1, 4.

2. Nobis PN, Hajong A. Eclampsia in India Through the Decades. J Obstet Gynaecol India. 2016 Oct; 66 (Suppl 1): 172-6. doi: 10.1007/s13224-015-0807-5. Epub 2016 Jan 8 .

\section{Phuapradit W,Suropa N,Harravasion}

S, Thuvasethalkul P. Serum level of Magnesium attained in Magnesium Sulphate therapy for severe preeclampsia. Asian Ocenia Journal Obste-Gynecology, Dec 1993; 19(4): 387-390.

4. Which anticonvulsant for women with eclampsia? Evidence from the Collaborative Eclampsia Trial. Lancet. 1995 Jun 10; 345 (8963) : 1455-63.

5. Sardesai Suman, Maira Shivangali, Patil Ajit, Patil Uday. Low dose Magnesium sulphate therapy in eclampsia and imminent Eclampsia; regime tailored for Indian Woman. Journal of Obstetrics and Gynecology India, 2003; Vol. 53, No.6:546-550. 
6. Witlin AG. Prevention and treatment of eclamptic convulsions. Clin Obstet Gynecol. 1999 Sep; 42(3): 507-18.

7. Geographic variation in the incidence of hypertension in pregnancy. World Health Organization International Collaborative Study of Hypertensive Disorders of Pregnancy. Am J Obstet Gynecol. 1988 Jan; 158(1): 80-3.

8. Begum R, Begum A, Johanson R, Ali MN, Akhter S. A low dose ("Dhaka") magnesium sulphate regime for eclampsia.Acta Obstet Gynecol Scand. 2001 Nov;80 (11):998-1002.

9. Ruchira Nautiyal,Akansha Shrivastav,Nidhi Chauhan, Hemant kumar Nautiyal. Feasibility of low dose magnesium sulphate for eclampsia- a randomized study. Indian Journal of Obstetrics and Gynecology research 2016;3(2):121-125.

10. Regmi MC, Aggrawal A, Pradhan T, Rijal P, Subedi A, Uprety D. Loading dose versus standard regimen of magnesium sulphate in eclampsia--a randomized trial. Nepal Med Coll J. 2010 Dec;12(4):244-7.

11. Begum MR, Begum A, Quadir E Loading dose versus standard regime of Magnesium sulphate in the management of Eclampsia: A randomized control trial. J. Obstetrics and Gynecology Research, June 2002, 28 (3): 154-159

12. Jana N, Dasgupta S, Das AK, Santra D, Samanta B. Experience of a low-dose magnesium sulfate regimen for the management of eclampsia over a decade. Int $\mathbf{J}$
Gynaecol Obstet. 2013 Jul;122(1):13-7. doi: 10.1016/j. ijgo.2013.01.029. Epub 2013 Apr 12.

13. Ahmed R. Magnesium sulphate as an anticonvulsant in the management of eclampsia. J Coll Physicians Surg Pak. 2004 Oct;14(10):605-7.

14. Bhattacharji N, Saha SP, Ganjuly RP. A randomized comparative study between low dose Intravenous Magnesium sulphate and standard intramuscular regimen in treatment of eclampsia. Journal of Obst and Gynecology 2011;31(4):298-303.

15. Choudhary $\mathrm{P}$ Eclampsia : a hospital based retrospective study.Kathmandu University Medical Journal, Vo.1, No. 4, issue 4, 237-41

16. Ekele BA, Muhammed D, Bello LN, Namadina IM. Magnesium sulphate regimen in eclampsia: the Sokoto (ultra short) regimen. BMC Research notes.2009;2: $165-8$.

17. Shilva, Saha SC, Kalra J, Prasad R. Safety and efficacy of low-dose MgSO4 in the treatment of eclampsia. Int J Gynaecol Obstet. 2007 May;97(2): 150-1. Epub 2007 Mar 21.

18. Pritchard JA, Cunningham FG, Pritchard SA. The Parkland Memorial Hospital protocol for treatment of eclampsia: evaluation of 245 cases. Am J Obstet Gynecol. 1984 Apr 1;148(7):951-63.

19. Sibai BM. Magnesium sulfate is the ideal anticonvulsant in preeclampsia-eclampsia. Am J Obstet Gynecol. 1990 May;162(5):1141-5.

\section{How to cite this article?}

Patil M, Dube A. H, Purwar M. Comparative study of low dose magnesium sulphate regime with Pritchard regime in eclampsia. Int J Med Res Rev 2017;5(05):478-483. doi:10.17511/ijmrr. 2017.i05.07. 